\title{
Perancangan Jaringan Voice Over IP (VoIP) Berbasis Raspberry Pi Untuk Sistem Komunikasi Area Remote
}

\author{
Harnan Malik Abdullah \\ Program Studi Teknik Telekomunikasi Politeknik Kota Malang \\ Jln Tlogowaru 3 Malang, 0341-754088 \\ e-mail: harnan@poltekom.ac.id
}

\begin{abstract}
Abstrak - Telekomunikasi saat ini sudah menjadi kebutuhan dasar manusia. Infrastruktur telekomunikasi dibangun di seluruh negeri untuk melayani kebutuhan tersebut. Namun area layanan yang ada masih belum bisa menjangkau seluruh wilayah terutama daerah-daerah terpencil (remote). Penelitian ini bertujuan untuk merancang sistem komunikasi berbasis VoIP yang bisa dimanfaatkan untuk komunikasi antar warga terutama di area yang minim infrastruktur telekomunikasi. Server VoIP dibuat menggunakan Raspberry Pi. Sedangkan fungsi router dan pemancar menggunakan Mikrotik Routerbord 433 dengan antena eksternal. Sedangkan perangkat yang digunakan oleh pengguna (client) bisa berupa handphone android, laptop maupun personal komputer. Hasil pengujian menunjukkan bahwah panggilan dan percakapan bisa dilayani oleh server Voip. Analisa QOS dengan metode MOS menunjukkan bahwa server VoIP hanya bisa melayani 10 percakapan pada saat bersamaan. Adapun jarak jangkau layanan untuk daerah LOS bisa mencapaijarak 500 meter.
\end{abstract}

Kata kunci: jaringan komunikasi, VOIP, raspberry pi, mikrotik

\section{Pendahuluan}

VoIP (voice over internet protocol) merupakan teknologi telekomunikasi yang berbasis IP. Teknologi ini memanfaatkan jaringan komputer untuk memberikan layanan kepada pengguna [3]. Jaringan komputer tersebut bisa berupa jaringan kabel maupun nirkabel (wireless). Sehingga, apabila terdapat pemancar jaringan komputer nirkabel maka komunikasi VoIP bisa diimplementasi di area jangkauan pemancar tersebut.

Penggunaan telepon berbasis VoIP memberi banyak keuntungan. Secara infrastruktrur lebih sederhana sehingga dari segi biaya jelas lebih murah dari biaya telepon tradisional. Hal ini karena VoIP dapat dipasang di sembarang Ethernet dan IP address, tidak seperti telepon tradisional yang harus mempunyai port tersendiri di Sentral atau PBX. Dalam merencanakan suatu jaringan VoIP, harus memiliki suatu server yang berfungsi sebagai IP PBX. Server tersebut dapat berupa komputer yang terinstall software server VoIP seperti asterisk, 3CX, $\mathrm{dsb}[2,5]$.

Raspberry Pi merupakan satu produk komputer mini yang saat ini banyak beredar di pasaran. Meskipun hanya seukuran kartu kartu kredit, perangkat ini memiliki kemampuan setara komputer pentium 4. Sistem operasinya dapat berbasis linux, windows, bahkan android. Dibandingkan dengan komputer biasa, rasberry pi memiliki kelebihan yaitu bentuknya yang kecil sehingga mudah dibawa dan dengan daya maksimal hanya 5 watt (untuk raspberry pi tipe B) $[1,6]$. Oleh karena itu, perangkat lunak server VoIP dapat diinstall di raspberry pi karena perangkat ini sama seperti komputer biasa yang menggunakan sistem operasi tertentu.

Telekomunikasi saat ini sudah menjadi kebutuhan dasar manusia. Infrastruktur telekomunikasi dibangun di seluruh negeri untuk melayani kebutuhan tersebut. Namun area layanan yang ada masih belum bisa menjangkau seluruh wilayah terutama daerah-daerah terpencil (remote). Oleh karena itu, diperlukan suatu sistem telekomunikasi yang

TELKA, Vol.2, No.1, Mei 2016, pp. 36 43

ISSN: 2502-1982 
memungkinkan untuk dipasang secara independen (tidak tergantung oleh infrastruktur yang sudah ada). Pada penelitian ini, dirancang sebuah jaringan VoIP berbasis Raspberry Pi dengan menggunakan jaringan wifi yang bisa digunakan sebagai alat komunikasi antar warga khususnya di daerah yang belum terjangkau layanan telekomunikasi.

\section{Research Method}

Penelitian ini bersifat implementatif yang dilakukan dengan dua proses yaitu merancang/membuat jaringan VoIP kemudian dilanjutkan dengan pengujian terhadap kinerja dari jaringan tersebut. Perancangan yang dilakukan meliputi perancangan perangkat keras dan konfigurasi perangkat lunak untuk membuat layanan VoIP secara nirkabel menggunakan pemancar wifi. Pengguna VoIP bisa menelpon antara satu dengan yang lain asalkan masih berada pada jangkauan sinyal wifi dari pemancar. Blok diagram keseluruhan sistem ditunjukan pada Gambar 1 dibawah ini.

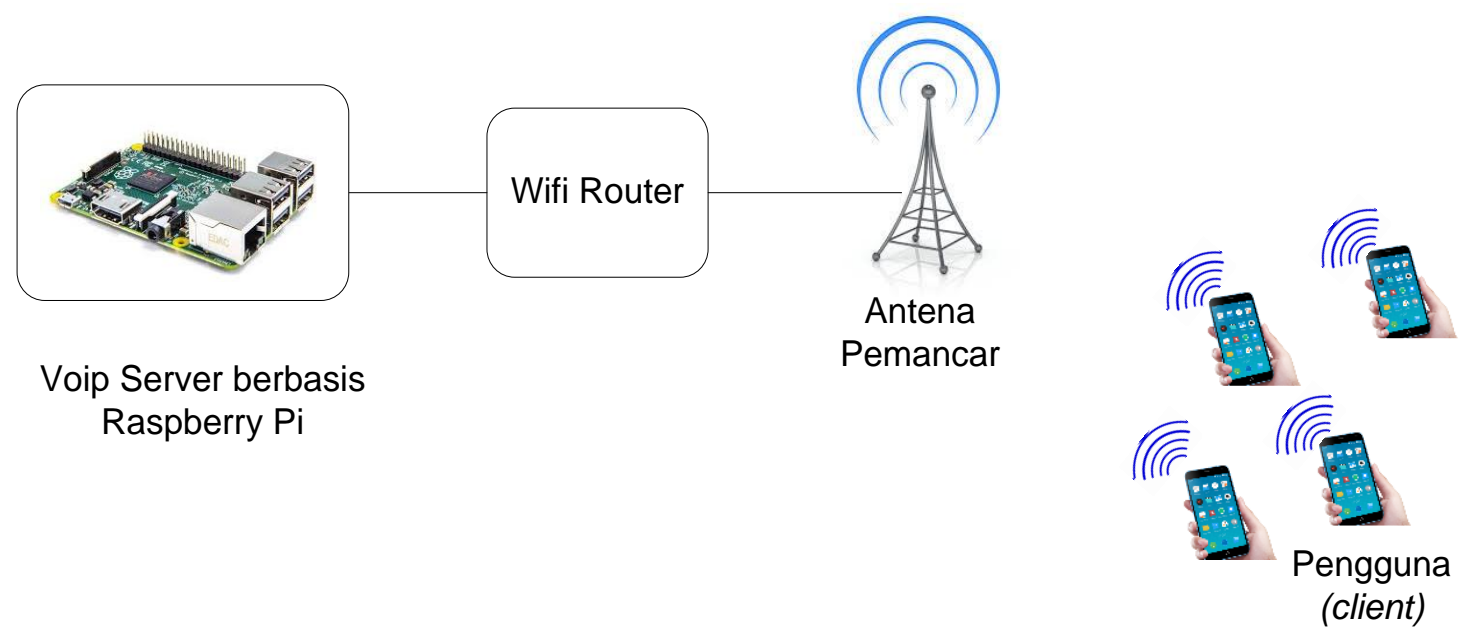

Gambar 1 Blok Pemancar VoIP

Dari blok diagram tersebut, terdapat beberapa bagian antara lain sebagai berikut:

1. Voip Server: merupakan perangkat utama yang berfungsi dari pusat layanan VoIP yaitu meregistrasi nomor pengguna, menyambungkan panggilan, memonitor percakapan, dll. Hardware yang digunakan adalah Raspberry Pi 2 dengan sistem operasi Raspbx.

2. Wifi Router: Perangkat ini berfungsi sebagai router yang menghubungkan secara nirkabel (wireless) antara server dengan pengguna serta memberikan alokasi alamat IP kepada pengguna yang melakukan akses ke jaringan. Adapun perangkat yang digunkan adalah Mikrotik Routerbord 433.

3. Antena Pemancar: berfungsi untuk menerima/memancarkan sinyal wifi dari dan ke pelanggan. Antena yang dipakai adalah antena luar jenis omnidirectional dengan ketinggian setidaknya $12 \mathrm{~m}$ dengan gain ditentukan diatas $10 \mathrm{dBi}$. Ketinggian ini dipakai dengan asumsi sudah melebihi rata-rata tinggi rumah di pedesaan sehingga mengurangi kerugian transmisi.

4. Perangkat Pengguna: menggunakan handphone android yang terinstall perangkat lunak VoIP seperti 3CX, SoftPhone, Zoiper, dsb. Laptop ataupun PC juga bisa dipakai sebagai perangkat pengguna.

Untuk membuat server VoIP, software RasPBX diinstall di raspberry pi. RasPBX merupakan sistem operasi untuk raspberry pi yang khusus dibuat untuk IP PBX. Dengan demikian, tidak perlu lagi instalasi perangkat lunak seperti database, web server, juga software asterisk karena secara otomatis sudah terinstall di sistem operasi RasPBX. Sehingga extensi dari masing-masing client tinggal di konfigurasi di server.

Pengujian dari sistem bertujuan untuk melihat unjuk kerja dari jaringan VoIP yang sudah dibuat. Ada dua pengujian yang dilakukan yaitu: pengujian fungsionalitas sistem dan pengujian 
kualitatif. Pengujian fungsional bertujuan melihat fungsi sistem yang dibuat untuk melakukan panggilan dan percakapan. Selain itu, jangkauan sinyal pemancar juga akan diukur berdasarkan jarak pada lingkungan LOS. Untuk pengujian sinyal ini, pemancar akan diletakkan di suatu tempat dengan ketinggian 12 meter lalu dilakukan pengecekan sinyal terima di area sekitar pemancar tersebut.

Pengujian kualitatif dilakukan dengan metode Mean Opinion Score atau MOS memberikan nilai angka sebagi indikasi kualitas yang dirasakan dari suara yang diterima dengan variabe total percakapan aktif yang sedang dilayani oleh server Voip. MOS merupakan sistem penilaian yang berhubungan dengan kualitas suara yang didengar pada ujung pesawat penerima. Standar penilaian MOS dikeluarkan oleh ITU-T pada tahun 1996. Tabel 1 adalah tabel yang menunjukkan skala penilaian MOS. MOS memberikan penilaian kualitas suara dengan skala 1(satu) sampai 5 (lima), dimana satu mempresentasikan nilai kualitas suara yang paling buruk dan lima mempresentasikan kualitas suarayang paling baik. Penilaian dengan menggunakan MOS masih bersifat subyektif karena kualitas pendengaran dan pendapat dari masing-masing pendengar berbeda-beda. Kategori telepon yang baik menurut ITU-T jika nilai MOS diatas 2,6 [2].

Tabel 1. Skala Penilaian MOS

\begin{tabular}{|l|l|}
\hline Kualitas Percakapan & Nilai \\
\hline Sangat Baik (Excellent) & 5 \\
\hline Baik (Good) & 4 \\
\hline Cukup Baik (Fair) & 3 \\
\hline Kurang Baik (Poor) & 2 \\
\hline Buruk (Bad) & 1 \\
\hline
\end{tabular}

Perhitungan Mean Opinion Score (MOS):

$$
\text { MOS }=\frac{\sum x(i) * k}{N}
$$

Dimana :

$\mathrm{X}(\mathrm{i})=$ Nilai Sample ke i

$\mathrm{K}=$ jumlah bobot

$\mathrm{n}=$ jumlah Pengamatan

\section{Hasil dan Pembahasan}

\subsection{Pengujian Server VoIP}

Pengujian server VoIP dilakukan dengan menggunakan dua buah laptop yang terinstall software VoIP client yaitu Zoiper seperti Gambar 2. Nomor ekstensi masing-masing client diregister di server VoIP kemudian dilakukan panggilan antara client 1 dan client 2. Sepuluh kali panggilan dilakukan dan hasilnya panggilan telepon berhasil dilakukan dengan suara yang jelas. Hasil ini menunjukkan bahwa server VoIP dapat bekerja dengan baik dan bisa melayani panggilan. 


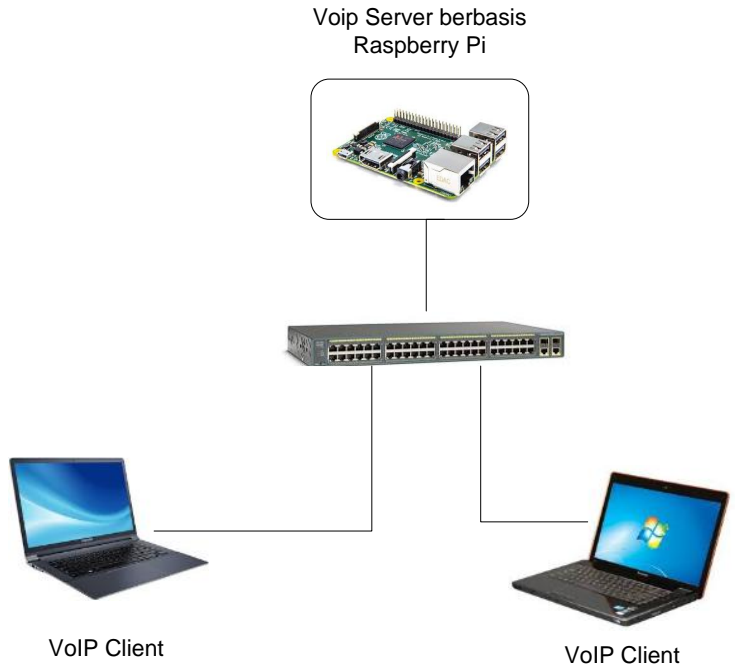

Gambar 2. Pengujian Funsionalitas Server VoIP

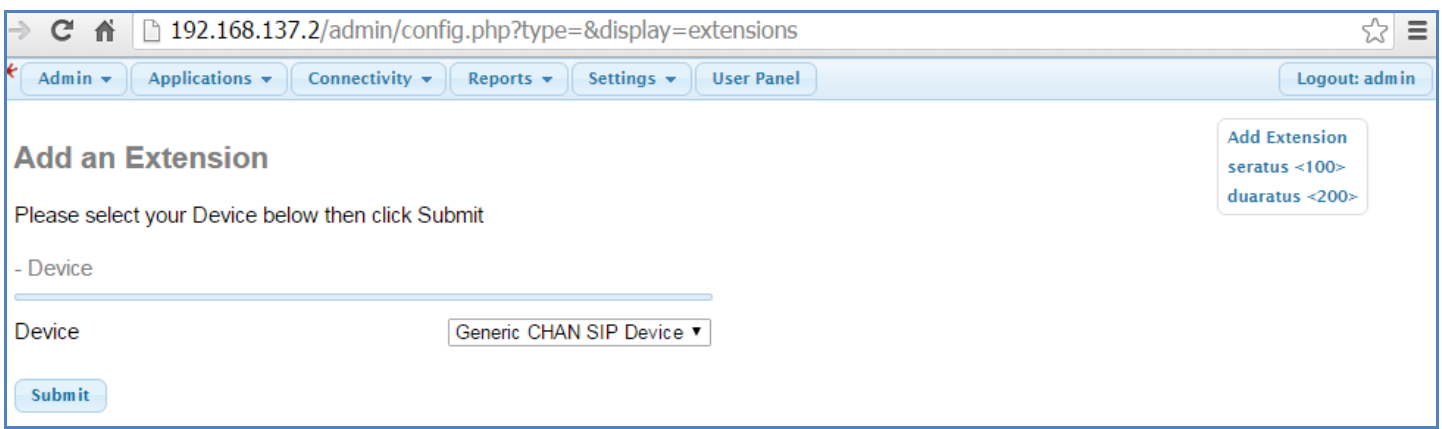

Gambar 3. Tampilan Server VoIP

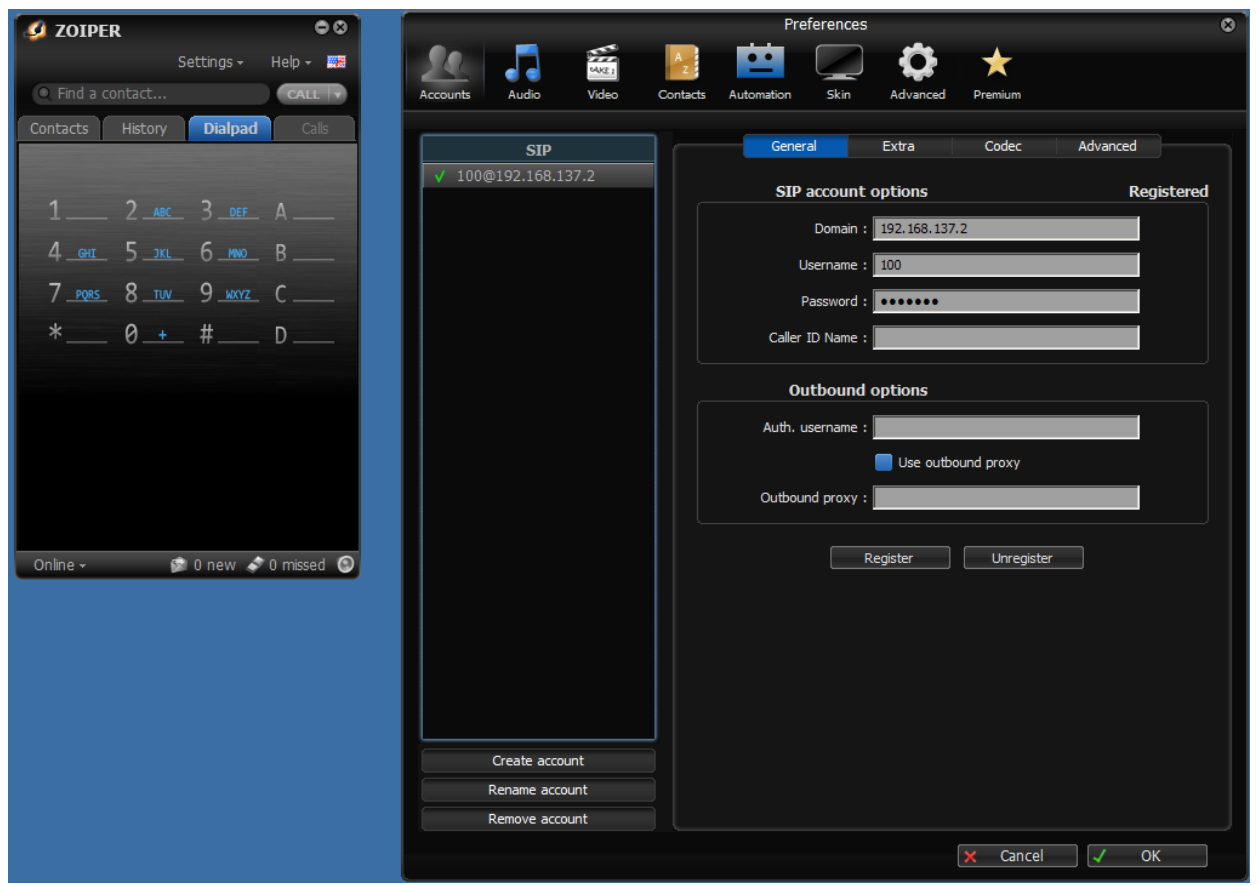

Gambar 4. Tampilan Software Client dengan Nomor Ekstensi 100 


\subsection{Pengujian Koneksi Client ke Server Melalui Pemancar Wifi}

Pengujian ini dilakukan dengan menghubungkan seluruh perangkat yang digunakan yang bertujuan untuk menguji koneksi pada layer network. Blok diagram pengujian seperti ditunjukkan Gambar 5. Mikrotik RB433 berfungsi untuk memancarkan sinyal wifi sekaligus menghubungkan ke server VoIP raspberry pi. Test ping dari client ke server berhasil dilakukan. Dengan demikian, perangkat jaringan wifi sudah berfungsi sesuai dengan yang direncanakan.
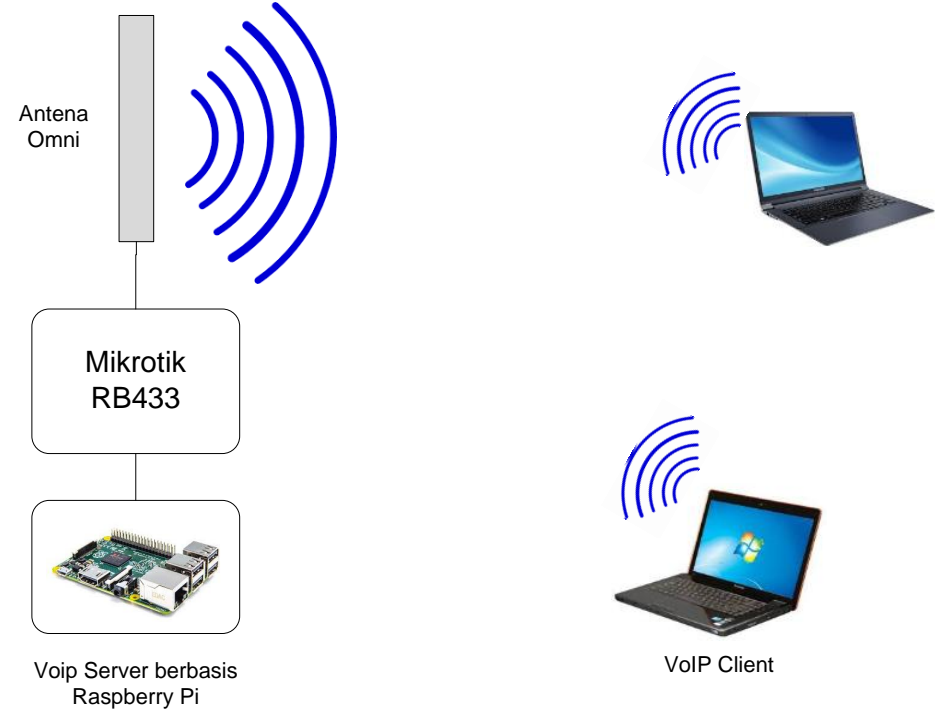

Gambar 5. Pengujian Koneksi Client ke Server

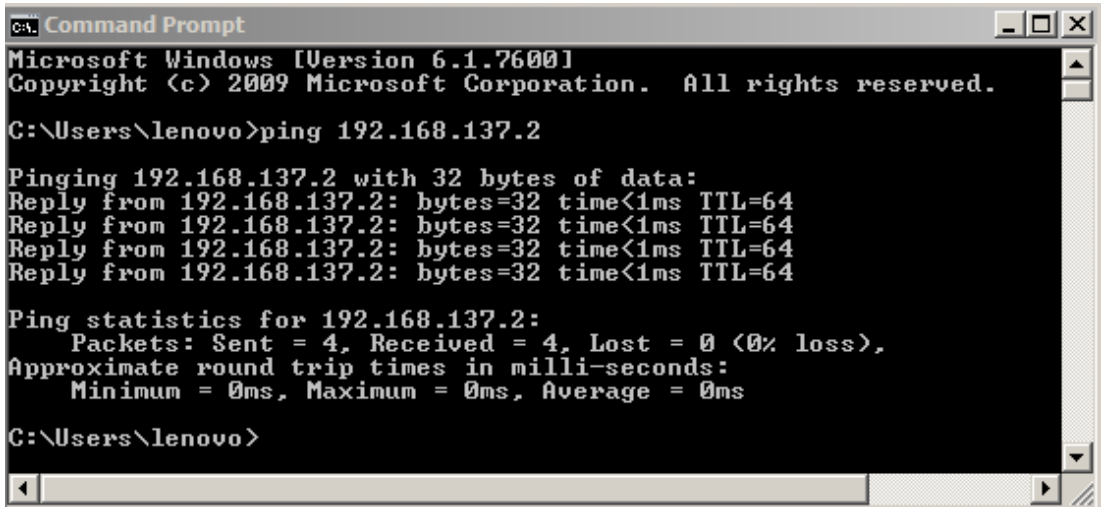

Gambar 6. Tes Ping dari Client ke Server

\subsection{Pengujian Keseluruhan Sistem}

Gambar 7 merupakan sistem pemancar VoIP yang telah dibuat. Untuk menguji keseluruhan sistem, dilakukan dua tahap pengujian. Pengujian pertama dilakukan untuk menguji kemampuan server untuk melayani panggilan percakapan dalam waktu yang bersamaan. Pengujian dilakukan di Laboratorium Jaringan Komputer Poltekom dengan mengacu pada blok diagram pada Gambar 4. Client yang digunakan berjumlah 24 client yang terdiri dari 20 PC, 2 buah laptop, dan 2 buah handphone. Semua client menggunakan Zoiper sebagai software VoIP. Untuk melihat kualitas percakapan dari panggilan, MOS digunakan untuk analisa QOS VoIP. 


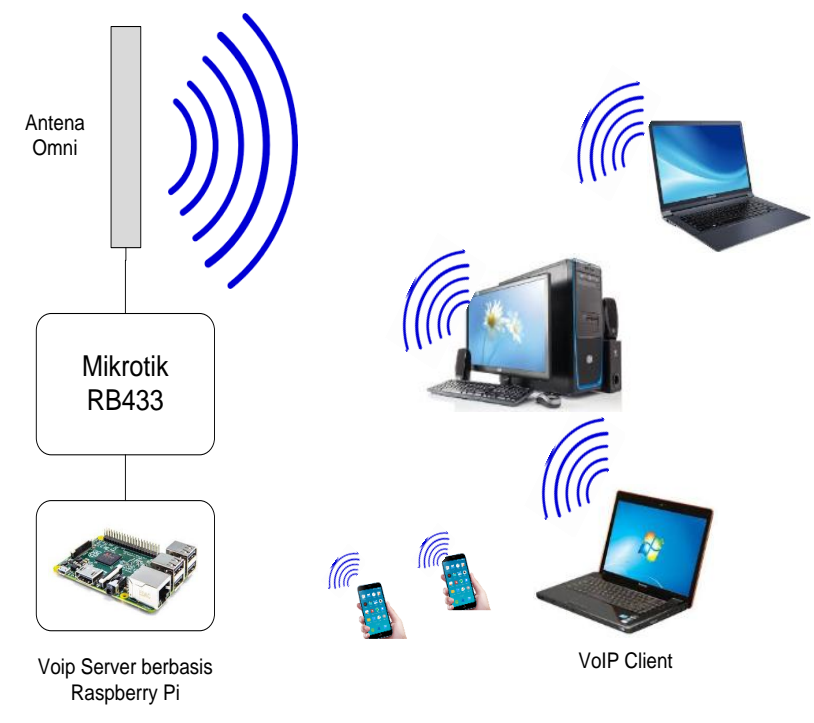

Gambar 7. Blok Diagram Pengujian Keseluruhan Sistem

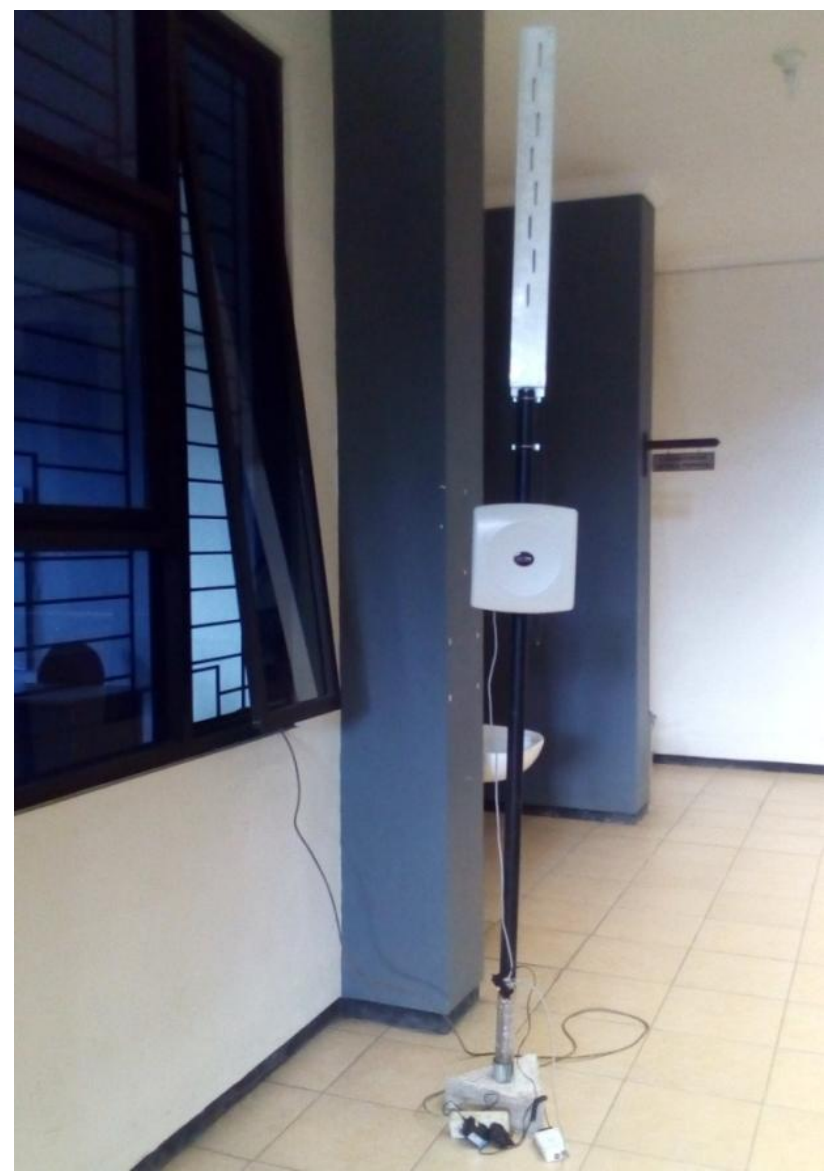

Gambar 8. Foto Pemancar VoIP

Sistem Pengujian keseluruhan sistem dilakukan dengan dua tahap. Tahap pertama untuk melihat kualitas layanan VoIP dengan variabel jumlah panggilan percakapan yang bersamaan. Sedangkan tahap kedua melihat kualitas layanan VoIP berdasarkan jarak antara pemancar dan client. Untuk tahap pertama, jarak antara pemancar dengan client maksimal 5 meter. Diasumsikan sampai pada jarak tersebut faktor jarak transmisi masih belum berpengaruh. Pada tahap ini diawali dengan melakukan 1 percakapan antara dua buah client. Lima orang responden 
menilai kualitas dari percakapan yang dirasakan. Kemudian dilanjutkan dengan 2 buah panggilan dan seterusnya hingga 12 panggilan. Adapun grafik kualitas layanan (QOS) sesuai dengan analisa MOS berdasarkan hasil uji pengujian ditunjukkan pada Gambar 9. Sesuai dengan standar ITU-T, kualitas telepon termasuk kategori baik jika memiliki nilai MOS lebih dari 2,6. Dari grafik tersebut, kualitas dibawah standar terjadi ketika jumlah percakapan diatas 10. Dengan demikian, server VoIP ini hanya mampu melayani maksimal 10 percakapan secara bersamaan.

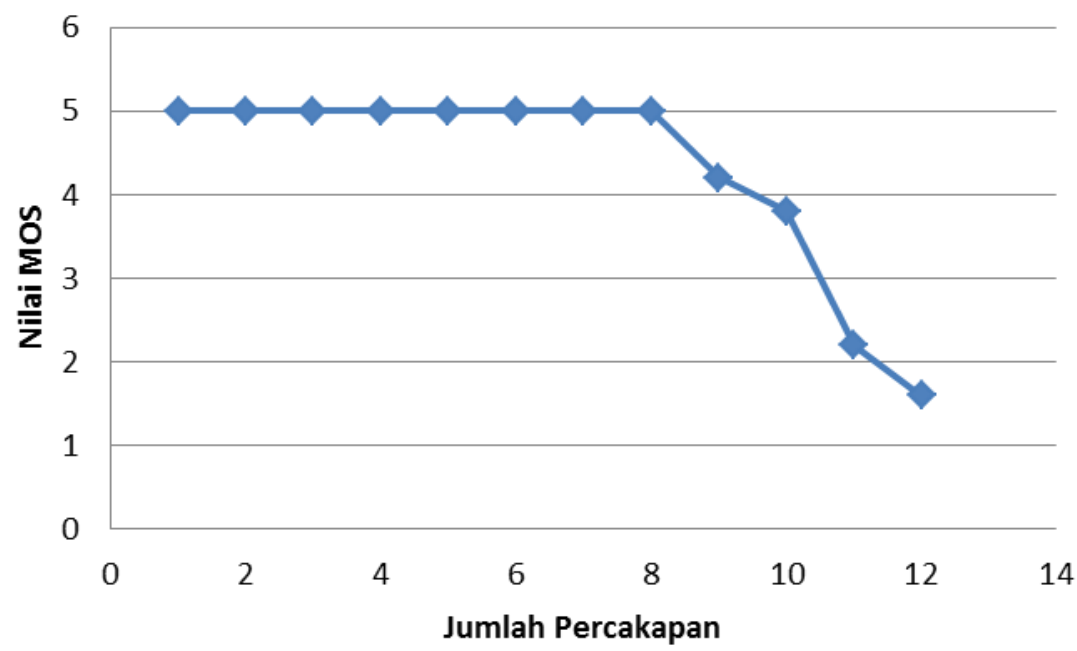

Gambar 9. Hasil Pengujian QOS Pemancar VoIP Berdasarkan Jumlah Percakapan

Pengujian jarak layanan dilakukan dengan meletakkan pemancar di atas gedung kampus Poltekom dengan ketinggian 12 meter. Hasil pengujian ditunjukkan pada Gambar 10. Dari hasil tersebut, kualitas layanan sudah menurun untuk jarak diatas 500m antara pemancar VoIP dan client VoIP.

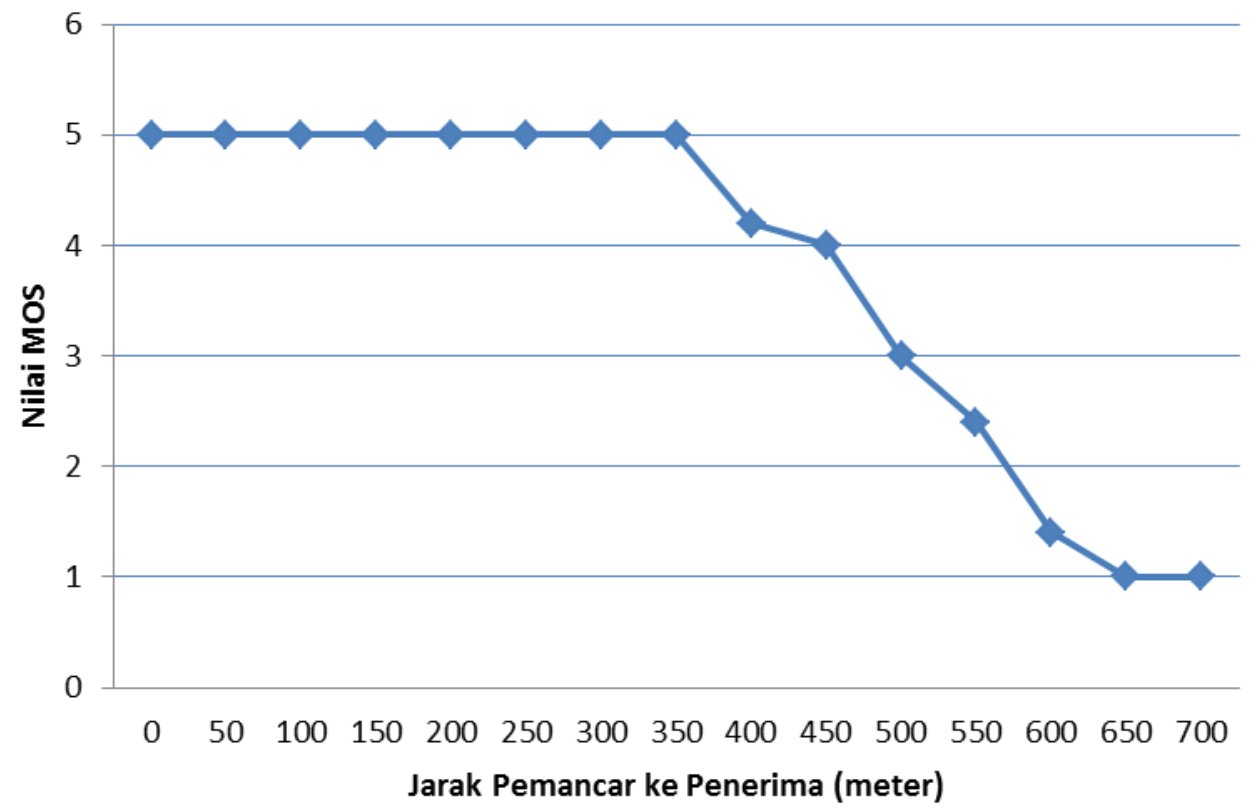

Gambar 10. Hasil Pengujian QOS VoIP Berdasarkan Jarak Pemancar dan Penerima 


\section{Kesimpulan}

Hasil dari penelitian ini menunjukkan bahwa raspberry pi dapat dimanfaatkan untuk server voip. Dengan kombinasi perangkat mikrotik routerboard 433, server voip tersebut dapat digunakan untuk sarana komunikasi secara nirkabel. Ini dapat dimanfaatkan untuk komunikasi pada daerah yang belum ada layanan dari infrastruktur telekomunikasi. Dari hasil pengujian, jarak jangkau layanan dapat mencapai jarak 500 meter. Jumlah percakapan yang bisa dilayani secara bersamaan (concurrent call) maksimal 10 percakapan. Penelitian ini belum mencangkup penelitian codec yang dipakai, semua client hanya menggunakan codec GSM. Penelitian lanjutan yang dapat dilakukan diantaranya peningkatan jarak pancar jaringan wifi agar area layanan lebih luas, penelitian akan codec yang dipakai, serta peningkatan kemampuan server voip dengan menggunakan dua buah atau lebih raspberry pi yang bekerja secara paralel.

\section{Acknowledgment}

Penulis mengucapkan terima kasih kepada Direktur Politeknik Kota Malang, Dr. Isnandar, MT atas dorongan dan kebijakan pendanaan kepada dosen untuk melakukan penelitian mandiri. Penulis juga berterima kasih kepada LPPM Poltekom arahan dan bimbingannya sehingga terselesaikannya penelitian ini. Dan juga, terima kasih kepada rekan-rekan dosen dan teknisi Prodi Teknik Telekomunikasi Poltekom atas bantuan dan saran-sarannya.

\section{Daftar Pustaka}

[1] Asadi, Aaron. 2014. Raspberry Pi The Complete Manual. Imagine Publishing Ltd. United Kingdom.

[2] Cahyono, Heru. 2012. Implementasi Server VoIP IP PBX untuk Meningkatkan Kualitas Layanan PABX. Skripsi tidak Diterbitkan. Malang: Universitas Kanjuruhan Malang.

[3] Lazuardi, Novri. 2008. Perencanaan Jaringan Komunikasi VOIP (Voice Over Internet Protocol) Menggunakan Asterisk SIP (Session Initiation Protocol). Skripsi tidak Diterbitkan. Medan: Fakultas Teknik-Universitas Sumatera Utara.

[4] Mustaqim, Fahmi. 2012. Implementasi Voice Over VPN Menggunakan IPv4. Skripsi tidak Diterbitkan. Bandung: Politeknik Telkom Bandung.

[5] Nadzif, Khusni. 2014. Implementasidan Analisis Kinerja VoIP Server Menggunakan Trixbox CE dengan Keamanan Jaringan VPN. Skripsi tidak Diterbitkan. Yogyakarta: Universitas Islam Negeri Sunan Kalijaga Yogyakarta.

[6] Robinson, Dr. Andrew. 2014. Raspberry Pi Projects. Indianapolis Composition Services. United Kingdom. 